\title{
Misio kritikorako MCPTT zerbitzuaren integrazioa 5G-NFV ertzeko konexio-sare batean
}

\author{
(Integration of the mission critical MCPTT service into a 5G-NFV \\ edge network)
}

\author{
Javier López-Cuadrado*1, Bego Blanco ${ }^{1}$, Elisa Jimeno ${ }^{2}$, \\ Miguel Catalan-Cid ${ }^{3}$,Eneko Atxutegi ${ }^{4}$ \\ ${ }^{1}$ Bilboko Ingeniaritza Eskola (UPV/EHU) \\ ${ }^{2}$ Atos Spain \\ ${ }^{3}$ i2CAT Foundation, Bartzelona \\ ${ }^{4}$ Nemergent Solutions, Bilbo
}

\begin{abstract}
LABURPENA: 5G teknologiaren helburu handienetako bat da egungo komunikazio-ekosistema hobetzea. Helburu hori lortzeko, etorkizun handiko irtenbidea da ertzeko konexio-sareen erabilpena, batez ere misio kritikoko zerbitzuak erabiltzen direnean, ertzeko konexio-sareek konputazio-mailan eta komunikazio-trukeari dagokion abiaduran ekartzen dituzten garapenak baliatu ahal izatean. Testu hau MCPTT zerbitzuan ardaztuko da; hau da, gaur egungo larrialdi-talde koordinatuei ahots-komunikazio klasikoa eskaintzen dion horretan. MCPTT zerbitzua $5 \mathrm{G}$ ekosisteman integratzearen erronka nagusiak zerikusia du horren funtzionamenduaren orkestrazioarekin, hain zuzen ere MCPTT zerbitzuak sareko azpiegitura beste hainbat zerbitzu eta sareko operadorerekin partekatu behar baitu. Artikulu honetan, software bidez definitutako sare-funtzioak eta sare-funtzioak birtualizatzeko estandar teknologikoak konbinatzen dituen arkitektura bat proposatzen da, 5G estandarrarekin bat datorrena. Ertzeko cluster batean, slicing sareko arkitekturaren birtualizazio-mekanismoa erabiliz, MCPTT zerbitzua nola hedatu den ere azaltzen da. Zehazki, MCPTT sareko funtzio birtuala osatzen duten unitateak deskribatzen dira. Bestalde, sistema osoaren orkestrazioa alertak arintzeko modulu batekin batera lan egiten duen monitorizazio-sistema batean oinarritzen da. Monitorizazio-sistemak zerbitzuaren eragiketarekin, baliabideen erabilerarekin edota irrati bidezko sarbidearen operazioarekin zerikusia duten hainbat parametro jaso eta biltzen ditu denbora errealean, eta, irakurritako balioen arabera, bi alerta mota eman ditzake: batetik, baliabide birtualei dagozkienak bereizten dira, eta, bestetik, irrati-baliabideei eragiten dietenak. Azkenik, MCPTT zerbitzua hedatu ondoren lortutako emaitzak ere aurkezten dira. Horretarako, lehenik eta behin, zerbitzuaren funtzionamendua dinamikoki doitzeko erabili diren monitorizazio -metrikak deskribatzen dira, eta, jarraian, sistemaren probak gauzatzeko zehaztutako agertokiak aurkezten dira. Emaitzen arabera, sistemak agertokietako eskaerei espero bezala erantzuten diela eta bere funtzionamendua dinamikoki ondo egokitzen duela frogatu da.
\end{abstract}

HITZ GAKOAK: MCPTT zerbitzua, 5G sareak, sare-funtzioen birtualizazioa, orkestrazioa.

ABSTRACT: One of the major objectives of $5 G$ technology is to improve the current communication ecosystem. The use of edge networking is a promising solution to this goal, especially when critical mission services are used. This text will focus on MCPTT, a service that provides a coordinated emergency team with classic voice communication. The main challenge in integrating the MCPTT service into the $5 G$ ecosystem relates to the orchestration of its operation, as the MCPTT service has to share the network infrastructure with many other services and network operators. This paper presents an architecture that is in accordance with the $5 G$ standard and at the same time combines software-defined networking and network functions virtualization. It also shows how MCPTT service has been deployed in a data center located at the edge, by using the slicing network architecture virtualization mechanism. Specifically, the units that constitute the MCPTT virtual network function are described. The orchestration of the entire system is based on a monitoring system that works in conjunction with an alert module. The monitoring system receives in real time and gathers a number of parameters related to service operation, use of resources, and operation of radio access, and may provide two types of alert according to the values read: on the one hand, those related to virtual resources, and, on the other, those alerts affecting radio resources. Results obtained after deploying the MCPTT service are also presented. For this purpose, first, the monitoring metrics used to dynamically adjust the operation of the service are described, and then the defined testing scenarios are presented. Results show that the system responds as expected to the different demands of the scenarios, and also that it dynamically adjusts its functioning properly.

KEYWORDS: MCPTT service, $5 G$ networks, network functions virtualization, orchestration.

* Harremanetan jartzeko / Corresponding author: Javier López-Cuadrado. Lengoaia eta Sistema Informatikoak Saila, Bilboko Ingeniaritza Eskola, Euskal Herriko Unibertsitatea (UPV/EHU). Rafael Moreno «Pitxitxi», 3. 48013 Bilbo (Bizkaia). javilo@ehu.eus - https://orcid.org/0000-0002-2801-0839

Nola aipatu / How to cite: López-Cuadrado, Javier; Blanco, Bego; Jimeno, Elisa; Catalan-Cid, Miguel; Atxutegi, Eneko (2021). "Misio kritikorako MCPTT zerbitzuaren integrazioa 5G-NFV ertzeko konexio-sare batean». Ekaia, 40, 2021, 375-388. (https://doi.org/10.1387/ekaia.22476).

Jasotze-data: 2020, urtarrilak 20; Onartze-data: 2021, martzoak 29.

ISSN 0214-9753 - eISSN 2444-3581 / (c) 2021 UPV/EHU

(i) (-) $\odot$ Lan hau Creative Commons Aitortu-EzKomertziala-LanEratorririkGabe 4.0 Nazioartekoa lizentzia baten mende dago 
Javier López-Cuadrado, Bego Blanco, Elisa Jimeno, Miguel Catalan-Cid, Eneko Atxutegi

\section{SARRERA}

5G teknologiaren helburu handienetako bat da egungo komunikazioekosistema hobetzea, transmisio-abiadura handiagoak, latentzia txikiagoak, energia-kontsumo murriztuagoa, teknologia merkeagoak, gaitasun handiagoa, eta interkonektagarritasun masiboa emanez [1]. Ertzeko Konexio Sareen (Edge Networking, EN) [2] erabilpena etorkizun handiko irtenbidea da helburu hori lortzeko [3]. EN teknologia baliabide informatikoak sare mugikorraren ertzeko cluster batean hedatzean datza. Baliabide horiek hainbat prozesamendu eta kontrol-lan egiteaz arduratuko dira, sarearen nukleoan trafiko-fluxua oztopatzea saihestuz tokian bertan kudea daitezkeen egoeretan.

Egoera hau bereziki interesgarria da Behe Latentziako Komunikazio Ultra Fidagarriak (Ultra Reliable Low Latency Communications, URLLC) behar dituzten egoeretan; adibidez, Misio Kritikoko (Mission Critical, MC) zerbitzuak erabiltzen direnean. Hain zuzen ere, 5G teknologiak bete behar duen errendimenduaren funtsezko adierazleetako bat lotuta dago MC zerbitzuen hornidurarekin [4]. Orain arte, zerbitzu horiek garestiak diren eta zerbitzu-hornitzailearen mende dauden sare jabeetan baino ez dira erabili. MC zerbitzuak 5G ekosisteman integratzean datza erronka, EN ingurunea aprobetxatuz eta, aldi berean, sareko azpiegitura beste zerbitzu eta sareko operadore batzuekin partekatuz. Horrek esan nahi du egoera normal batean lehentasunezkoak ez diren zerbitzuak erabiltzen arituko dela batez ere sarea, eta MC zerbitzuei esleitutako baliabideak gutxi izango direla. Hala ere, larrialdi-egoera batean, MC zerbitzuei baliabide gehiago esleitzen hasiko zaie. Kasu horretan, gerta liteke gainerako zerbitzuen kalitatea murriztea edo etetea. Eta sarea nukleotik isolatuta dagoen ezohiko egoera batean ere, EN arkitektura batek ertzeko baliabide guztiak MC zerbitzuei esleitzea ahalbidetu lezake, komunikazio kritikoen jarraitutasuna bermatu ahal izateko.

MC transmisioetan latentziak minimizatu nahi badira, sare-azpiegitura behar bezala prestatu behar da. Horretarako gehien erabiltzen den ereduetako bat Software bidez Definitutako Sare-funtzioak (SoftwareDefined Networking, SDN) [5] eta Sare Funtzioak Birtualizatzeko (Network Functions Virtualization, NFV) [6] estandar teknologikoak konbinatzean datza; eredu horrek ertzean funtzionaltasuna malgutasunez eta ekonomikoki hedatzea ahalbidetzen du. Slicing izeneko sare birtualeko mekanismoak [7] SDN eta NFV tekniken abantailak aprobetxatzen ditu sareko arkitekturaren birtualizazioa eskaintzeko. Hain zuzen ere, azpiegitura fisiko beraren gaineko sare birtual ugari definitzeko aukera ematen du [8]. Xafla edo slice bakoitzak sare birtual horietako bakoitza osorik hedatzeko aukera ematen duten sare-funtzioak eta baliabide logikoak ditu [9]. Testuinguru horretan, sareko slicingak aukera ematen du az- 
piegitura fisiko beraren gainean elkarren artean isolatuta dauden zerbitzu ugari elkarrekin bizitzeko, eta, gainera, malgutasunez lortzen du; hau da, slice bakoitzaren gaitasunak egokitzen ditu baliabideak modu eraginkorragoan erabiltzeko. Hortaz, erronka zera da: hainbat zerbitzu behar dituzten aktoreei erabilgarri dauden baliabide komunak espazioan zein denboran dinamikoki eta modu gardenean esleitzea. Horretarako, sareak gai izan beharko luke bere portaera automatikoki aldatzeko, adibidez, funtzioak aldatuz, parametro batzuk birkonfiguratuz edo, kasu muturrekoagoetan, sarearen ertzean zerbitzu jakin batzuk egikaritzea hedatuz. Puntu honetan, sliceak kudeatzeko prozesuek eskatzen dute denbora errealeko monitorizazio-sistema baten bidez NFV arkitekturari buruzko hainbat adierazle biltzea eta prozesatzea. Gainera, sistema horrek gai izan behar du erreakzionatzeko eta arintze-ekintza egokiak martxan jartzeko, baldin eta sare birtualaren konfigurazioan aldaketaren bat egin behar dela antzematen badu.

Testu hau MC ahots-zerbitzuaren kasu berezi batean zentratuko da; alegia, Hitz egiteko-Sakatu MC (Mission-Critical Push-To-Talk, MCPTT) zerbitzuan [10]. Sareko zerbitzu horrek walkie-talkieetan oinarritutako ahots-komunikazio klasikoa eskaintzen dio larrialdi-talde koordinatu bati, hala nola polizia, suhiltzaile edo anbulantzia-zerbitzu bati. MCTPP zerbitzuak baldintza zorrotzak betetzea eskatzen du; bereziki, komunikazioen eskuragarritasun- eta fidagarritasun-indize altuak, latentzia oso baxuak, elkarrizketetan parte hartzen duten erabiltzaileen identifikazioa, eta audioaren kalitate ona. Larrialdi-taldeak azpitaldetan antolatu ohi direnez, MCPTT zerbitzuak puntuz puntu eta taldeko deien artean bereiztea eskatzen du. Dei mota edozein dela ere, erabiltzaile bakar batek (floor kontrola esleituta duenak) hitz egin dezake, eta gainerakoek entzun besterik ezin dute egin. Erabiltzaile batek baino gehiagok sakatzen dutenean hitz egiteko baimena eskatzeko balio duen botoia, MCPTT zerbitzuak arbitrajea egin behar du zer eskaera onartu behar den zehazteko, eta gainerako eskaerak baztertzea edo itxaronaldian jartzea erabakitzeko. Erabaki hori hainbat parametroren arabera hartzen da - hala nola, erabiltzaileen lehentasuna-; izan ere, gerta liteke lehentasun handiagoa duen erabiltzaile batek hitz egiten ari den erabiltzailea etetea, hau da, floor kontrola kentzea.

Hurrengo atalak EN teknologian oinarritutako $5 \mathrm{G}$ arkitektura bat proposatzen du; ondoren, 3. atalean, arkitektura horretan egindako MCPTT zerbitzuaren hedapena deskribatzen da. Laugarren atalak zerbitzua sarean hedatu ondoren lortutako emaitzak aurkezten ditu; horretarako, lehenik eta behin, zerbitzuaren funtzionamendua dinamikoki doitzeko erabili diren monitorizazio-metrikak aurkezten dira, eta, jarraian, sistemaren probak egiteko zehaztutako agertokia deskribatzen da. Amaitzeko, 5. atalak ondorio garrantzitsuenak laburbiltzen ditu. 
Javier López-Cuadrado, Bego Blanco, Elisa Jimeno, Miguel Catalan-Cid, Eneko Atxutegi

\section{PROPOSATUTAKO EN ARKITEKTURA}

5G azpiegituraren Elkarte Publiko Pribatua (5G Public Private Partnership, 5G PPP) Europako Batzordearen eta Informazioaren eta Komunikazioaren Teknologien (IKT) inguruko industria europarraren arteko ekimen bateratua da; bertan IKT fabrikatzaileak, telekomunikazio-operadoreak, zerbitzu-hornitzaileak, Pymeak eta ikerketa-erakundeak daude ordezkatuta. Testu honetan, 5G-PPP programak deskribatzen duenarekin bateragarria den 5G arkitektura bat proposatzen da [11], non Irrati bidezko Sarbide Sare (Radio Access Network, RAN) partekatuak kudeatzeko 3GPP estandarra eta sarefuntzioak birtualizatzeko ETSI NFV egitura konbinatzen baitira (1. irudia).

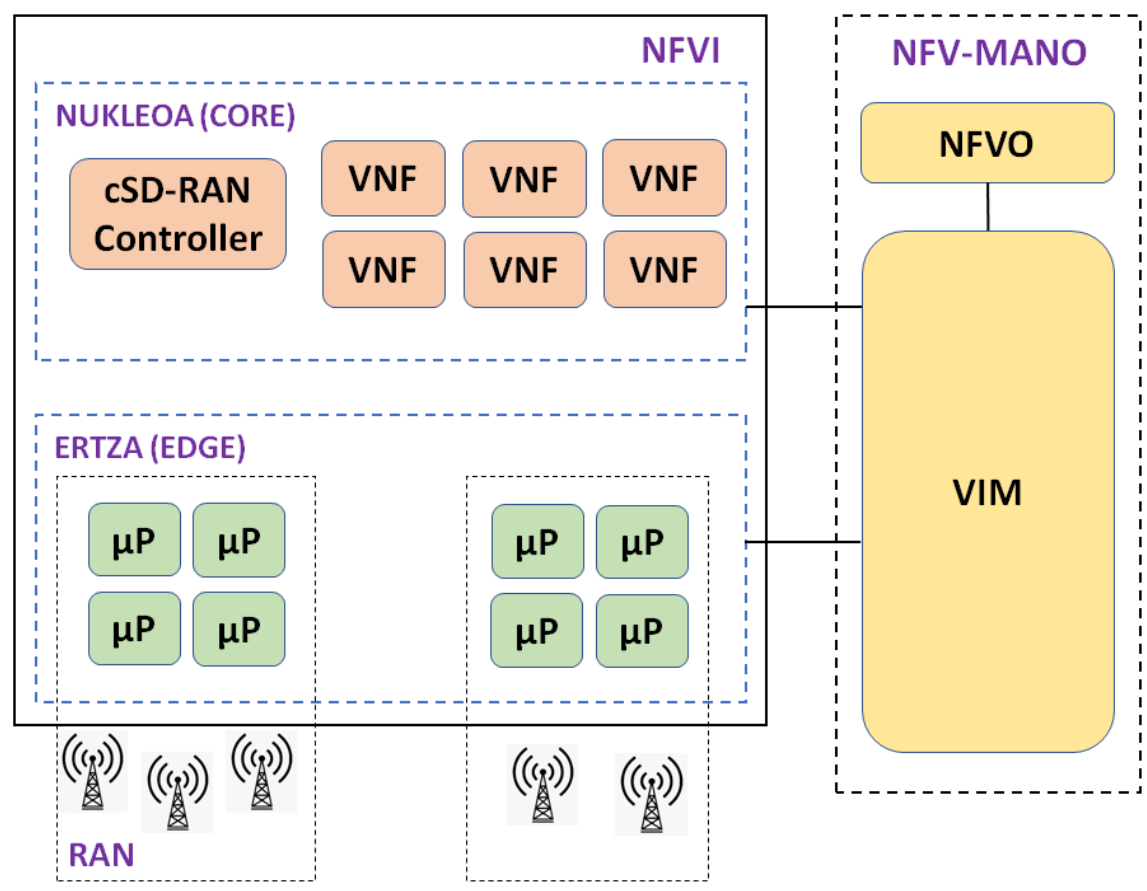

1. irudia. Proposatutako EN sare-arkitektura.

EN teknologiaren eredua jarraituz, sare mugikorraren ertzean cluster bat edo gehiago kokatzen dira, sarearen nukleoan trafikoa murrizteko asmoz hainbat prozesamendu eta kontrol-ataza gauzatzen dituztenak. Horrela, NFV azpiegitura (NFV Infrastructure, NFVI) bi geruzatan banatzen da: alde batetik, nukleoak (Core goi-geruzak), prozesatze-botere altua eskaintzen duena, eta konputazio-behar intentsiboak eskatzen dituzten sareaplikazioak Sareko Funtzio Birtual (Virtual Network Functions, VNF) gisa 
egikaritzen dituena; eta, bestalde, ertzak (Edge geruzak), erabiltzailearen hurbilago banatutako geruza. Nukleoak ertzaren komunikazioen kontrola zentralizatzen du, eta han gertatzen denaren ikuspegi osoa dauka.

Software bidez Definitutako Irrati bidezko Sarbide Sare Kontrolatzaile Zentralizatua (centralised Software Defined RAN Controller, cSD-RAN Controller) ertzaren erradio-baliabideen gaineko kontrol-planoan erabakiak hartzen dituen VNFa da, bereziki sarerako sarbideei dagokienez. Egon daitezkeen RAN desberdinak hodeitzat jotzen direnez, slicing teknikak hainbat sare-operatzaileri aukera ematen die beren erabiltzaileenganako zerbitzuak hornitzea baimentzeko. Ildo horretan, Hodeirako Irrati bidezko Sarbide Sareaz (Cloud-Enabled RAN, CE-RAN) hitz egiten da, Irrati bidezko Sarbide Teknologia (Radio-Access Technology, RAT) mota ugari barne hartu ditzakeelako: 5G, LTE eta WiFi, besteak beste.

EN arkitektura kudeatzeko erabiltzen den modulu nagusia NFV-MANO da. Modulu horrek antenak kontrolatu eta koordinatzen ditu sareko zerbitzuak gauzatu daitezen. Hainbat modulu ere baditu, baina oraingoz bi baino ez dira interesgarriak: NFV Orkestratzailea (NFVO) eta Birtualizatutako Azpiegitura Zuzendaria (Virtualised Infrastructure Manager, VIM).

NFVO moduluak SDNren eragiketa kudeatzen du, eta, beraz, sareko zerbitzuen katalogoa eta exekuzioa kontrolatzen ditu. Sareko zerbitzuen bizi-zikloa kudeatzeaz ere arduratzen da, zerbitzua hedatzen denetik amaitzen den arte. Sareko operadore batek eskatzen duen zerbitzu bakoitzagatik, NFVO moduluak zerbitzu hori osatzen duten VNFak egikaritzea hedatzen eta koordinatzen du. Exekuzioa nola hedatu behar den erabaki ondoren, VIM modulua arduratuko da VNF bakoitzari dagozkion baliabide fisikoak esleitzeaz.

NFV-MANO moduluak hainbat RAN kudea ditzake. Horretarako, sarbide-sare bakoitza bere VIMa duen cluster independentetzat hartzen da. Proposatutako arkitekturan, VIM zuzendaria ertzeko geruza kudeatzeko asmoz nukleoan egikaritzen den Open Stack softwarearen instantzia bat da. Hain zuzen ere, VIMek bitartekari-lanak egiten ditu NFV-MANOren eta RANen artean. Oro har, baliabide fisiko eta birtual guztiak kudeatzen ditu, eta, beraz, baliabide birtualizatu bakoitza zein baliabide fisikori dagokion erregistratzen du. Gainera, VIM zuzendariak sliceak esleitzen dizkie sareoperatzaileei, eta, ondorioz, beren arteko isolamendua bermatzen du.

EN arkitekturetan oraindik ez dago orkestrazio-sistemaren inplementazio estandarizaturik, sliceen independentziari eragin gabe baliabideak denbora errealean esleitzeari dagokionez behintzat. Hainbat ekimen daude implementazio horren inguruan; horien artean, alertak arintzeko modulu batekin batera lan egiten duen monitorizazio-sistema batean oinarritutako aukera bat aurkeztuko da [12]. 
Monitorizazio eta Alertak Arintzeko Moduluak (Monitoring and Alert Mitigation Module, MAMM) NFVOren eta RANen kontrol-funtzioak sostengatzen eta hobetzen ditu, orkestrazio-prozesuari inteligentzia ematen baitio erabakiak hartzeko momentuan. MAMM arduratzen da monitoriza daitezkeen gainerako sare-elementuen (batik bat, NFVI, cSD-RAN Controller eta unean zerbitzua ematen ari diren VNFak) datu-esportatzaileek sortutako informazio diagnostikoa biltzeaz, prozesatzeaz eta interpretatzeaz.

cSD-RAN kontrolatzaileak erradio atalaren egoerari buruzko informazioa ematen du, hala nola zirkulazioaren bolumenari edo banaketa geografikoari buruzkoa. Bestalde, une horretan egikaritzen ari diren VNFetatik eta NFVOtik lortzen dira hodeiko errendimendu-neurriak. Makina birtualen errendimendu-adierazleek, hala nola CPUen egoerak edo RAM memoriaren eskuragarritasunak, hardware-azpiegituraren egoeraren irudi orokor bat eskaintzen diote MAMM moduluari. Horretaz gain, zerbitzu-errendimenduari buruzko adierazleek aukera ematen dute sareko operadoreekin hitzartutako Zerbitzu Mailari buruzko Akordioak (Service Level Agreement, SLA) betetzen ari diren ala ez zehazteko.

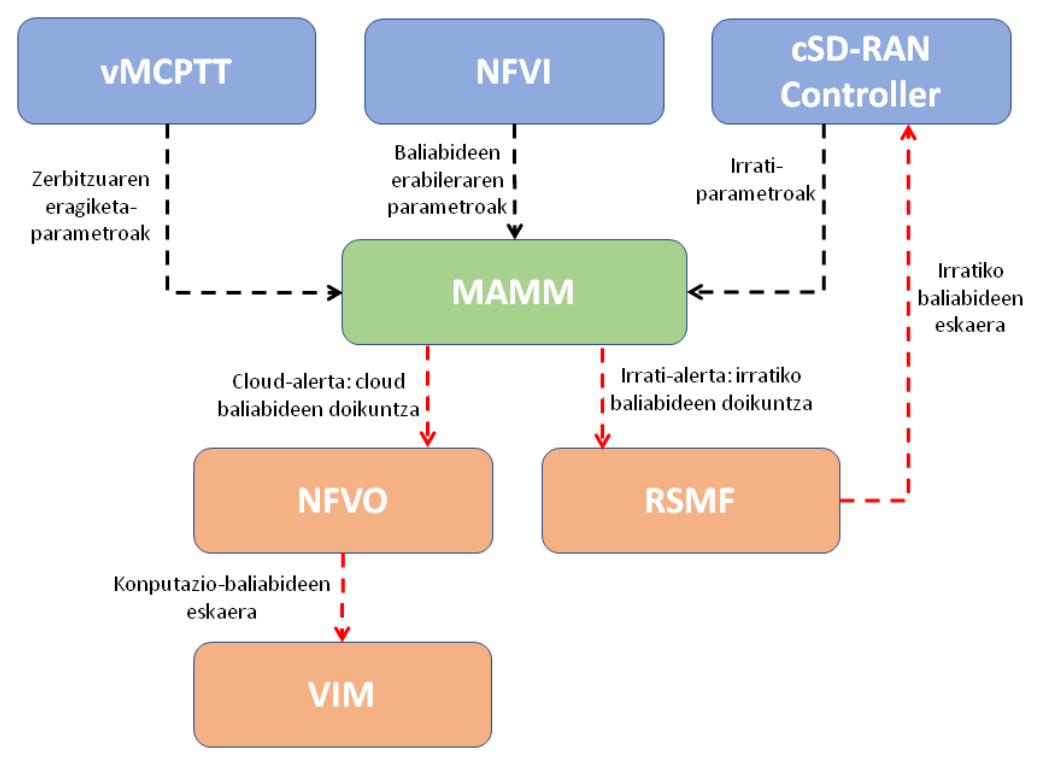

2. irudia. Mutur batetik besterako slicingaren kudeaketarako gertaera-jarioa.

2. irudian azaltzen da MCPTT zerbitzu bateko mutur batetik besterako slicingaren kudeaketa adierazten duen gertaera-jarioa. Bertan ikus daiteke MAMM modulua, aldez aurretik definitutako arau batzuk betetzen 
diren ala ez kontuan hartuta, gai dela alerta-mezuak igortzeko, eta mezu horiek, egoeraren arabera, NFVOrantz edo RAN Xaflatze Kudeaketa Funtziorantz (RAN Slicing Management Function, RSMF) zuzenduko dituela. RSMF modulua NFVOren baliokidea da, baina irrati-baliabideen kontrolari aplikatuta. Alerta arintzeak sare birtualaren konfigurazioan doikuntzaren bat egitea ekarriko du, identifikatutako behar edota egoera berrietara egokitzeko. Horrela, NFVOrantz zuzendutako alerta bat igortzean, baliabide birtualetako bat aldatuko da (adibidez, VNF bat eskalatu edo beste makina birtual batean hedatuko da, erabiltzaile gehiagori zerbitzua eman ahal izateko), eta RSMFra zuzendutako alertek, berriz, irratiko baliabideei eragingo diete (adibidez, erabiltzaile aktiboen kopurua handitu ondoren, cSD-RAN kontroladoreak baliabide gehiago esleituko ditu audio-fluxuak denbora errealean transkodetu ahal izateko).

Sareko zerbitzu bat ertzean bertan hedatzen denean, zerbitzua eskaintzeko beharrezkoak diren VNFak makina birtual gisa Edge DCn exekutatzen dira. Hurrengo atalean vMCPTT deskribatuko da; hau da, ertzean MCPTT zerbitzua gauzatzeari dagokion VNFa.

\section{MCPTT ZERBITZUAREN ARKITEKTURA}

MCPTT estandarra MC ahots-zerbitzu bat da, bana-banako zein taldeen arteko deien bitartez larrialdi-taldeen koordinazioa errazten duena. Dei bakoitzean erabiltzaile bakar batek hitz egin dezake, floor kontrola delakoa duenak, alegia. Erabiltzaileek hitz egin nahi dutenean, baimena eskatzeko balio duen botoia sakatu behar dute, eta zerbitzuak erabakiko du nori esleitzen dion une bakoitzean floor kontrola. Adibidez, baliteke hitz egiten ari den erabiltzaileari etetea, lehentasun handiagoko beste erabiltzaile bati ahotsa emateko. Ondorioz, MCPTT zerbitzuaren kudeaketa ez da hutsala, ez bakarrik komunikazioa ahalbidetzeko lehentasunak eta pribilegioak behar bezala kudeatzea eskatzen duelako, baizik eta, MC zerbitzua denez, MCPTT zerbitzuak oso baldintza zorrotzak bete behar dituelako, hain zuzen ere URLLC komunikazio baterako eskatzen direnak.

MCPTT transmisioetan latentziak minimizatzeko, bi alderdi landu daitezke. Batetik, komeni da terminalen kodifikazio-denbora murriztea. Hori dela eta, orain arte sare jabeetan hedatutako MCPTT zerbitzuek transmisiogailu jabeak erabiltzea behartzen zuten. Hala ere, zerbitzua 5G sare ireki batean eman nahi denean, komunikazio-gailu generikoak erabiliko dira (adibidez, Android smartphoneak), eta, ondorioz, mota horretako terminaletan datu-paketeak kodetzeko eta deskodetzeko prozesua bizkortu behar da. Bestetik, gailuen arteko transmisioa-latentziak txikiagotzeko sareko azpiegitura prestatu behar da. Horretarako, EN arkitekturaren ezaugarriak aprobetxatuz, ertzean bertan heda daitezke Interneteko guneak normalean eskaintzen di- 
Javier López-Cuadrado, Bego Blanco, Elisa Jimeno, Miguel Catalan-Cid, Eneko Atxutegi

tuen zenbait funtzionalitate. Hala, zerbitzua emateko, Edge geruzak gaitasun lokalak eta erreplikatuak izango ditu esleituta; izan ere, larrialdi- edo isolamendu-egoera batean, MCPTT funtzionalitate guztia ertzean garatu beharko da nahitaez.

3. irudiak ertzean hedatutako MCPTT zerbitzuaren arkitektura erakusten du, vMCPTT izeneko VNF bakar batek osatzen duena. Eskura dauden baliabideen erabilera optimizatzeko, VNF hau zenbait Inplementazio Birtualeko Unitatez (Virtual Deployment Unit, VDU) osatuta dago; alegia, vDNS, vCSC, vIMS eta vMCPTT_AS.

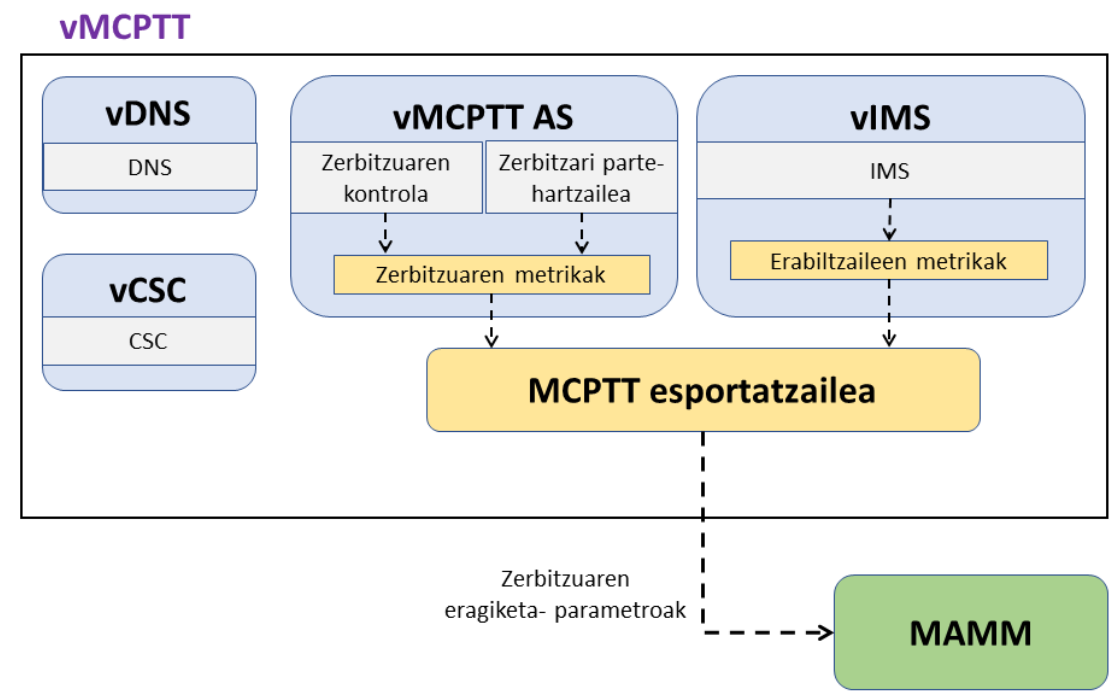

3. irudia. MCPTT zerbitzuaren arkitektura.

- vDNS. VDU hau Domeinu Izenen Sistema (Domain Name System, DNS) zerbitzaria da. Sareko beste DNS zerbitzariekin hierarkikoki antola daiteke.

- vCSC. VDU hau zerbitzuko egoeraren informaziorako erabiltzen den Ohiko Zerbitzu Nukleoa (Common Service Core, CSC) da. Aukera ematen du MCPTT zerbitzuaren egoerari buruzko informazioa kudeatzeko beste zerbitzari laguntzaile batzuen mende egoteko; hala nola, Talde Kudeaketa Zerbitzaria (Group Management Server, GMS), Identitate Kudeaketa Zerbitzaria (Identity Management Server, IDMS), Gako Kudeaketa Zerbitzaria (Key Management Server, KMS) edota Konfigurazio Kudeaketa Zerbitzaria (Configuration Management Server, CMS). 
- vIMS. VDU honek saioa hasteko protokoloa eta saioak kudeatzeko beharrezkoa den IP Multimedia Azpisistema (IP Multimedia Subsystem, IMS) zerbitzua inplementatzen ditu.

- vMCPTT_AS. VDU hau MCPTT zerbitzuaren eta deien kontrolaren laguntza zentralizatua ematen duen Aplikazio Zerbitzaria (Application Server, AS) da. Kontrol-lanak egin ditzake, hala nola floor kontrolari dagokionez arbitratzea edo dei batean baliabideen erabilera kudeatzea (adibidez, konferentzia, transkodifikazioa), eta baita parte hartzeko zereginak ere, hala nola puntuz puntuko eta taldeko deiak erabiltzaileen artean kontrolatzea.

MCPTT zerbitzua MAMM moduluak monitorizatutako orkestraziozikloan integratu ahal izateko, artikulu honetan proposatzen den arkitekturak MCPTT esportatzailea izeneko modulua erabiltzen du. Osagai honek 60 segundoro lortzen ditu monitorizazio-lanetarako behar diren metrikak, batez ere IMS eta MCPTT AS sistemetatik. Hurrengo atalean zehaztuko dira zein diren MCPTT zerbitzuak erakusten dituen metrikak.

\section{EMAITZAK}

Atal honetan, MCPTT zerbitzuaren slice bat (3. irudia) alertak monitorizatzeko eta arintzeko sistema bat (2. irudia) duen EN arkitekturan (1. irudia) integratzearen emaitzak aurkeztuko dira. Horretarako, lehenik eta behin, sareko elementuetatik bildutako metrikak adieraziko dira, eta baita larrialdiko gertaera bat detektatzen denean zehaztutako arintze-ekintzak ere. Ondoren, balidazio-agertokia deskribatu eta inplementazioaren emaitzak erakutsiko dira.

\subsection{Metriken monitorizazioa eta arintze-ekintzen definizioa}

MAMM moduluak hiru lekutatik jasotzen du sistemaren egoerari buruzko informazioa: azpiegituratik bertatik, SD-RAN kontrolatzailetik eta, kasu zehatz honetan, MCPTT esportatzailetik.

NFVIk eskaintzen duen informazio guztiaren artean, esperimentu honetan interesatzen zaiguna CPUri eta memoria erabiltzeari dagokiona eta makina birtualetako errendimenduari eta erabilgarritasunari buruzkoa da.

Bestalde, cSD-RAN kontrolatzaileak slice bakoitzeko RANen erabiltzaile kopuruari, transmititutako bit-tasei eta seinalearen kalitateari buruzko informazioa biltzen du. Identifikatutako metrika bakoitzerako, kontuan hartzen ditu bere neurketa-egitura eta izan daitezkeen alarmak. Alarmaren bi atalase-balio definitzen dira: lehenengoak ohartarazpen bat adierazten du; bigarrenak, berriz, egoera kritikotzat jotzen du. 
Javier López-Cuadrado, Bego Blanco, Elisa Jimeno, Miguel Catalan-Cid, Eneko Atxutegi

Azkenik, MCPTT esportatzaileak emandako informazioa datu orokorrek osatzen dute - hala nola, erregistratutako erabiltzaile kopuruak edo erabiltzaile aktiboen kopuruak - , eta baita datu partikularrek ere - hala nola, hasita, abian eta amaituta dauden deien kopuruak, bai eta dei mota bakoitzean (pribatuak, taldekoak, larrialdietako pribatuak, larrialdietako taldekoak) parte hartzen duten erabiltzaileen kopuruak ere- .

Hainbat metrika monitoriza badaitezke ere, kontzeptu-probetan dei aktiboen eta larrialdi-deien kopuruak bakarrik hartzen dira kontuan, hurrengo ataletan ikusiko den bezala.

\subsection{Agertokiaren definizioa eta hedapenaren emaitzak}

Dinamikoki orkestratutako MCPTT zerbitzuaren hedapenaren funtzionamendua aztertzeko, ezin da agertoki estatiko bat erabili. Izan ere, esperimentu honen helburuetako bat da frogatzea baliabideak behar bezala berresleitzen direla MAMM moduluak hautemandako larrialdi-baldintzen arabera. Beraz, hiru egoera proposatzen dira: normaltasuna, larrialdia eta isolamendua.

Normaltasun-egoeran, 5G sarearen jabea errutinaz ari da operadoreekin adostutako zerbitzuak ematen; hau da, horietako bakoitzari beharrezkoa den sare-slicea esleitzen ari zaio. Slice bakoitzaren ezaugarriak dira estalduraeremu bati buruzko datuak transmititzeko abiadura (irrati-baliabideen zati batean SD-RAN kontrolatzaileak mapeatzen duena) eta esleitutako hodeiko baliabide multzo bat (Edge geruza prozesatzeko eta biltegiratzeko ahalmenen zati batekin bat datorrena). RANek estalitako eremu horretan, MCPTT zerbitzua erabiltzen ari diren segurtasun publikoko erakundeei slice txiki-txikia esleitzen zaie, non sarbide eta komunikaziorako eskainitako baliabideak gutxieneko funtzionaltasuna (adibidez, une bakoitzean txanda egiten duten patruiletan egiten diren ohiko elkarrizketak) emateko mugatzen baitira. Beraz, egoera horretan, dei aktibo gutxi eta larrialdi-deirik ez egotea espero da.

Gertakari baten ostean larrialdi-taldeko kide batek larrialdi-dei pribatu bat egiten badu, orduan, larrialdi-egoerara pasatzen da. Monitorizazio-sistemak larrialdi-deien kopurua ez dela zero nabaritzen duen momentuan, NFV-MANOk zerbitzu-eskakizun berriei erantzuteko prest egon eta gai izan beharko du: MCPTT zerbitzuaren sliceari Edge geruzako baliabideak esleitzen hasiko da, geroz eta dei berri gehiago eta erabiltzaile berri gehiago izatearen arabera. MCPTT zerbitzuaren komunikazioak bermatu egin behar dira, lehentasunezkoak dira eta. Beraz, gerta daiteke gainerako zerbitzuen kalitatea murriztea; adibidez, vMCPTT funtzioa eskalatzeko orduan lehentasunik ez duten beste sliceen irrati bidezko zein hodeiko gaitasunak murriztea beharrezkoa denean.

Azkenik, isolamendu-egoera muturreko gertaera baten ondorioz agertzen da; esaterako, sare-azpiegitura kaltetuta dagoenean, hondamendi natural bat dela-eta, edo eraso terrorista baten ostean. Internetekiko konekta- 
garritasuna galdu da, eta, egoeraren larritasuna dela eta, ertzeko baliabide guztiak MCPTT zerbitzura bideratu behar dira. Horren ondorioz, lehentasunezkoak ez diren beste zerbitzuei esleitutako sliceak zerora murriztu dira. Irrati-estaldura zabaldu ahal izateko, larrialdi-zerbitzuek hartu beharreko lehen neurria sarerako sarbide-puntu berriak gehitzea litzateke; adibidez, base-guneetan kalteak arintzeko sistema hedagarriak erabili beharko lirateke, eremuan zabaldu diren kideei 5G konektagarritasuna eskaintzen diena eta elkarreragingarritasun-baldintzak finkatzen dituena. Irrati-transmisioak arazorik gabe orkestratu ahal izateko, berritzat hartzen da sistema hedagarri bakoitza dagokion clusterean dinamikoki integratu den RANa.

\subsection{Sistemaren egokitzapenaren emaitzak}

Planteatutako hiru agertokietan egindako probei esker, proposatutako plataformaren gaitasunak egiaztatu ahal izan dira; hain zuzen ere, aurreikusitako hiru egoeretan larrialdi-taldeari esleitutako irrati bidezko, sareko eta hodeiko baliabideak dimentsionatzeko gaitasuna; zerbitzuaren eskakizunetara egokitzeko sliceak dinamikoki birkonfiguratzeko edota beste batzuk sortzeko gaitasuna; une oro larrialdi-taldeari MCPTT zerbitzuaren erabilgarritasuna ziurtatzeko gaitasuna; eta sistema monitorizatzeko eta esleitutako baliabideak aldatu behar diren egoerak detektatzeko gaitasuna.

Lehen agertokian, lehentasun txikiko dei arruntak baino ez dira egiten. Halako batean, sistemak larrialdi-dei bat egin dela detektatzen du, eta dagokion alerta sortzen da. Alerta horren ondorioz, MCPTT zerbitzuari esleitutako baliabide kopurua handitzen da, krisi-egoera potentzial bat aurreikusi delako. Azkenik, monitorizazio-sistemak sarean edota zerbitzuan aldaketak hautematen dituen heinean, egokitzen doa zerbitzuaren funtzionamendua. Hurrengo irudiak orkestrazio-prozesuaren funtzionamendua azaltzen duen dashboardaren edo panelaren zenbait pantaila-argazki biltzen ditu: goiko argazkiak esperimentuan erabili diren metriken monitorizazioa erakusten du, eta bertan ikus daiteke nola hauteman diren gertaerak denboran zehar. Lehenengo pantaila-argazki honek bereziki esperimentuan zehar une oro izan den dei kopurua aurkezten du, lau grafikotan, dei moten arabera: puntuz puntukoak zein taldekoak, eta arruntak zein larrialdikoak. Lau grafiko hauei esker, denboran koka daitezke esperimentuak iraun duen tartean izan den dei bakoitzaren hasiera, iraupena eta amaiera. Erdiko pantailaargazkiak eragiketen erregistroaren zatitxo bat aurkezten du; hain zuzen ere, bigarren agertokian izan den alarmaren arintzeari dagokiona. Bertan ikus daiteke, espero zen moduan, alarma-arintze horren ondorioz vMCPTT funtzioa eskalatu dela. Azkenik, beheko pantaila-argazkiak hirugarren agertokian izan den irrati-slicearen birkonfigurazioa erakusten du. Bertan ikus daitekeen bezala, monitorizatutako dei aktibo kopurua igotzearen ondorioz MCPTT zerbitzuari geroz eta handiagoa den slicea esleitzen zaion heinean, txikituz doa kritikoa ez den beste komunikazio-zerbitzu bati esleitutako slicea. 
Javier López-Cuadrado, Bego Blanco, Elisa Jimeno, Miguel Catalan-Cid, Eneko Atxutegi

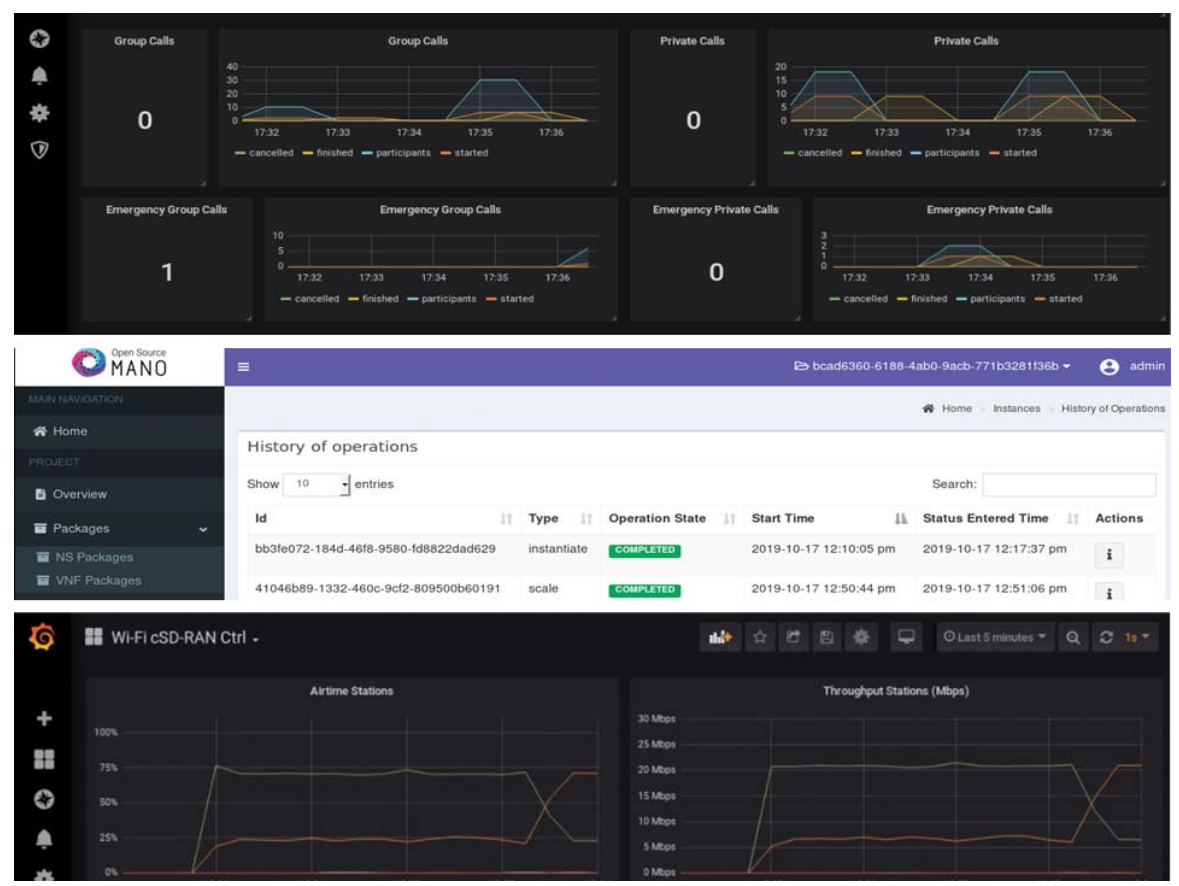

4. irudia. MCPTT zerbitzuaren orkestrazio-zikloaren pantaila-argazkiak.

Laburbilduz, sistemak espero bezala erantzun die agertokien eskaera desberdinei, eta dinamikoki egokitu du bere funtzionamendua horietako bakoitzean MCPTT estaldura egokia eman ahal izateko.

\section{ONDORIOAK ETA ETORKIZUNEKO LANAK}

Sareko zerbitzu baten betekizunak irratiko Errendimenduaren Funtsezko Adierazle (Key Performance Indicator, KPI) kopuru jakin batean biltzen dira, eta baita SLAk beteko direla bermatuko duen komunikazio-zerbitzuaren instantzia bat hedatzean ere. Operadore bakoitzaren zerbitzuaren kalitatea (Quality of Service, QoS) bermatzeaz gain, 5G sarearen jabeak ziurtatu behar ditu sliceen artean beharrezkoak diren isolamendu-mailak ere.

Aurkeztutako proba-agertokiarekin proposatutako arkitektura baliozkotzea lortu nahi izan da, batez ere latentzia baxuko zerbitzuek eskatzen dituzten muturreko slicing-gaitasunak emateko orduan. MC zerbitzuen funtzionamenduak (kasu honetan, MCPTTrena) ez du eragotzi behar lehentasunezkoak ez diren beste zerbitzuen funtzionamendu egokia, beste aukerarik ez dagoenean izan ezik. Beraz, sarbide-sarearen slicinga eta VNFen eskalatzea baliozkotu 
dira, MCPTT zerbitzurako muturretik muturrerako slicingaren bideratzaile gisa. Gaitasun berri horien ezaugarri esanguratsu bat da segurtasun publikoaren (Public Safety, PS) eta merkataritza-erabiltzaileen artean irrati bidezko eta hodeiko baliabideak partekatzea posible izango dela, betiere larrialdi-taldeek eskatzen duten kalitate handiko sarbidea bermatuz eta lehenetsiz.

Artikulu honek orkestrazio-ziklo adimenduna deskribatu du. Bertan ikusi da 5G teknologiak, muturretik muturrerako slicing malgu eta efizienterako soluzio bat emateaz gain, irrati bidezko eta hodeiko baliabideen orkestrazio eraginkorra ere berma dezakeela. Emaitzek sare partekatuaren ereduaren balioa nabarmentzen dute, eta beharrezkoa denean arkitekturak larrialdi-taldeei baliabideak modu autonomoan esleitzeko gaitasuna duela erakusten dute, baldintzak murriztaileak ez direnean merkataritza-zerbitzuei lagata. Automatikoki egiten da baliabideen esleipen dinamikoa, NFI-MANOko orkestrazio-prozesuak osatzen dituzten monitorizazio eta alertak arintzeko funtzionaltasunak aprobetxatuz.

Gure ikerketa-lanak orkestrazio-tresnak garatzen jarraituko du, NFV inguruneetako muturreko slicing gaitasunak hobetzeko. Ikerketa-joera berrien artean sartzen dira, besteak beste, erabakiak hartzeko prozesuan ikaskuntza automatikoko teknikak erabiltzea, alarmen arintze-prozesuan metrika gehiago integratzea, VNFen migratzea eta hedatzea, eta multi-RAT sarbide-aukerak aztertzea.

\section{ESKER ONAK}

Ikerlan hau, neurri batean, 5G Monitorizazio eta Mitigazio Orkestraketa (5G MoMo, ZL-2020/00830 beka zenbakiduna), MINECO PTQ-1709334 beka zenbakidun, eta 5G for Basque RIS3 (5G4BRIS3, KK-2020/ 00031 beka zenbakiduna) proiektuen baitan garatu da.

\section{BIBLIOGRAFIA}

[1] MARKAKIS, E. K., KARRAS, K., SIDERIS, A., ALEXIOU, G. eta PALLIS, E. 2017. «Computing, caching, and communication at the edge: The cornerstone for building a versatile $5 \mathrm{G}$ ecosystem». IEEE Communications Magazine, 55(11), 152-157.

[2] ETSI MEC ISG. 2014. Mobile Edge Computing - Introductory Technical WhitePaper, No 1. URLa: https://portal.etsi.org/Portals/0/TBpages/MEC/ Docs/Mobile-edge_Computing_-_Introductory_Technical_White_Paper_ V1\%2018-09-14.pdf (Eguneratze-data: 2020/12/31).

[3] 5G-PPP. 2015. 5G Vision: The next generation of communication networks and services. 5G Infrastructure Public Private Partnership. URLa: https://5g-ppp.eu/wp-content/uploads/2015/02/5G-Vision-Brochure-v1.pdf (Eguneratze-data: 2020/12/31). 
[4] LI, Z., UUSITALO, M. A., SHARIATMADARI, H. eta SINGH, B. 2018. «5G URLLC: Design challenges and system concepts». 2018 15th International Symposium on Wireless Communication Systems (ISWCS), 1-6. IEEE.

[5] JANZ, C., ONG, L., SETHURAMAN, K. eta SHUKLA, V. 2016. «Emerging transport SDN architecture and use cases». IEEE Communications $\mathrm{Ma}$ gazine, 54(10), 116-121.

[6] HAWILO, H., SHAMI, A., MIRAHMADI, M. eta ASAL, R. 2014. «NFV: state of the art, challenges, and implementation in next generation mobile networks (vEPC) ». IEEE Network, 28(6), 18-26.

[7] BARAKABITZE, A. A., AHMAD, A., MIJUMBI, R. eta HINES, A. 2020. «5G network slicing using SDN and NFV: A survey of taxonomy, architectures and future challenges». Computer Networks, 167, 106984.

[8] FOUKAS, X., ELMOKASHFI, A., PATOUNAS, G. eta MARINA, M.K. 2017. «Network Slicing in 5G: Survey and Challenges». IEEE Communications Magazine, 55(5), 94-100.

[9] MARTÍNEZ, R., VILALTA, R., CASELlAS, R., MUÑOZ, R., FEI, L., TANG, P. eta LÓPEZ, V. 2018. «Network Slicing Resource Allocation and Monitoring over Multiple Clouds and Networks». Proceedings Optical Fiber Communications Conference and Exposition (OFC), 1-3. IEEE.

[10] 3GPP. 2019. Mission Critical Push to Talk (MCPTT); Stage 1(Release 17) TS 22.179 v17.0.0. The 3rd Generation Partnership Project (3GPP). URLa: https://www.3gpp.org/ftp//Specs/archive/22_series/22.179/22179-h00.zip (Eguneratze-data: 2020/12/31).

[11] SPADA, M. R., PÉREZ-ROMERO, J., SANCHOYERTO, A., SOLOZABAL, R., KOURTIS, M. A. eta RICCOBENE, V. 2019. «Management of mission critical public safety applications: the 5G ESSENCE Project». 2019 European Conference on Networks and Communications (EuCNC), 155-160. IEEE.

[12] BLANCO, B., SOLOZABAL, R., SANCHOYERTO, A., LÓPEZ-CUADRADO, J., JIMENO, E. eta CATALAN-CID, M. 2020. «Intelligent Orchestration of End-to-End Network Slices for the Allocation of Mission Critical Services over NFV Architectures». IFIP International Conference on Artificial Intelligence Applications and Innovations, 74-83. Springer, Cham. 



